\title{
Occurrence and antibiotic susceptibility of Listeria monocytogenes along meat production chain in southwest Ethiopia
}

Seid Tiku Mereta ( $\nabla$ seidtiku@yahoo.com )

Jimma University College of Public Health and Medical Sciences

Beje Gume

Jimma University College of Public Health and Medical Sciences

Assegid Getaneh

Jimma University College of Agriculture and Veterinary Medicine

Yosef Deneke

Jimma University College of Agriculture and Veterinary Medicine

\section{Lelisa Sena}

Jimma University College of Public Health and Medical Sciences

Dechassa Tegene

Jimma University College of Agriculture and Veterinary Medicine

Tesfaye Kassa

Jimma University

Leykun Berhanu

Wollo University

Habib Bediru

Jimma University College of Agriculture and Veterinary Medicine

Sultan Suleman

Jimma University

Research article

Keywords: Abattoir, Antimicrobial, Butcher Shop, Meat, Listera, Listeriosis

Posted Date: May 3rd, 2020

DOI: https://doi.org/10.21203/rs.3.rs-25769/v1

License: (1) (1) This work is licensed under a Creative Commons Attribution 4.0 International License.

Read Full License 


\section{Abstract}

Background The widespread habit of consumption of raw meat along with poor hygiene during handling, transportation and processing are the major contributors to the high prevalence of food-borne diseases in Ethiopia. Listeriosis is one of the important food-borne diseases acquired through consumption of meat. The aim of this study was to assess the occurrence and antimicrobial susceptibility of Listeria species in meat collected from abattoir and butcher shops.

Methods A cross-sectional study was conducted from January 2018 to February 2019 on isolation, phenotypic characterization, and determination of antibiotic susceptibility profiles of isolates of $L$. monocytogenes. A total of 100 meat samples were collected from abattoir and butcher shops in Jimma Town. Laboratory based isolation and characterization of the Listeria species was made using conventional culture and biolog. Antimicrobial susceptibility test was conducted using ten different selected antibiotics of current veterinary and human therapy. An observational check list was used to assess meat handling practices of butcher shops and abattoir workers.

Results From the total of 100 samples collected from butcher shops and the abattoir, 29 (29\%; $95 \% \mathrm{Cl}$ : 21.0-38.5\%) were found positive for Listeria species. Out of this, 15 (30\%, 95\% Cl: 34.4-68.6\%) samples were from the butcher shops and $14(28 \%, 95 \% \mathrm{Cl}$ : $31.4-65.6 \%)$ were from the abattoir. L. innocua $(48.3 \%)$ was the dominant species followed by L. seeligeri (27.6\%). L. monocytogenes accounts $7 \%$ of the isolates. Antibiotic susceptibility tests revealed that $L$. monocytogenes isolates were susceptible to gentamicin, vancomycin, Sulfamethoxazole-Sulfamethrimethoprim, chloramphenicol and cloxacillin. In contrary, L. monocytogenes isolates were resistant to cloxacillin, penicillin, nalidixic acid and tetracycline. On the other hand, low level of education, lack of training on meat handling and poor cleanliness of meat contact surfaces were significantly associated with the occurrence of Listeria spp. $(P<0.05)$.

Conclusion The findings highlighted the need for regular training on hygienic meat handling practices for meat handlers in order to minimize the risk of food borne diseases. Furthermore, regulation of the optimal use of antimicrobials in food producing animals is highly recommended so as to reduce antimicrobial resistance.

\section{Background}

Food-borne diseases encompass a wide spectrum of illnesses and are growing public health problems worldwide. The global burden of food-borne diseases and its impact on development and trade is currently increasing in both industrialized and developing countries $[1,2,3]$. The diseases are caused by ingestion of a wide variety of foods contaminated with pathogenic microorganisms and microbial toxins. Food-borne diseases occur commonly in developing countries because of the prevailing poor food handling and sanitation practices, inadequate food safety laws, lack of financial resources to invest in safer equipment's, and lack of education for food-handlers $[4,5,6]$. 
Meat is an excellent source of protein in human diet and is highly susceptible to microbial contamination due to its nutritive value $[7,6]$. Although muscle of healthy animals does not contain microorganism, meat tissues get contamination during the multiple steps along the food production chain including production, processing, distribution, and handling or preparation in abattoirs and retail outlets $[8,9]$.

Listeriosis is an emerging bacterial zoonosis capable of causing severe food-borne infections both in humans and other animals worldwide. The genus Listeria includes a group of Gram-positive, non-spore forming, catalase-positive, oxidase negative, and facultative anaerobic bacteria. Among thirteen identified species of the group, L. monocytogenes is the only emerging food borne pathogen of high public health significance infecting humans and animals. While L. ivanovii is usually restricted to cause disease in ruminants, mainly sheep, other Listeria species are generally considered as non-virulent $[10,11,3]$. The species of Listeria are widely distributed in nature and have been isolated from soil, vegetation, sewage, water, and animal feed, fresh and frozen meat including poultry, slaughter house wastes and in the faces of healthy animals including human [12]. A number of food-borne out breaks caused by Listeria specie have been reported in different regions, especially in Europe and the USA. However, in most developing countries there are few reports on Listeriosis as compared to the Europe and the USA $[5,13,14]$. In Ethiopia, the wide spread habit of raw meat products consumption is a potential cause for food borne diseases. Raw meat products are available in open-air at local retail shops without appropriate temperature control. These products are purchased by households and served at home and restaurants as raw, slightly-cooked, or well heat treated. Meat processing at retail level is likely to contribute for the higher levels of contamination in minced beef (kitfo and dullet-local names) as compared to carcasses which are considered to be high risk for diseases and are suggested as possible reasons for the emergence of food-borne listeriosis $[15,16,2,17]$.

On other hand, the global increase in the incidence, prevalence, and antimicrobial resistance are being reported in recent years. Multiple drug resistance of bacterial pathogens severely limiting therapeutic option for infections in both animals and humans has increased concerns of food-borne diseases [18, 2 , 19]. The use of antimicrobials as prophylaxis or sub-therapeutic level in food producing animals has been a great concern, because it is believed to be an important factor in the emergence of strains of resistant to certain antimicrobials and markedly increase the human health risk associated with consumption of contaminated meat products $[2,20,21]$. In Ethiopia, only few researches have been reported on listeriosis and the antimicrobial susceptibility profile of Listeria isolates in animal products. As a result, this research was conducted with the aim of isolation, phenotypic characterization and antimicrobial susceptibility profile of Listeria species from bovine meat at municipal abattoir and butcher shop in Jimma Town.

\section{Materials And Methods}

\section{Study area and population}


The study was conducted in Jimma Town municipal abattoir and butcher shops. The town is located at $352 \mathrm{~km}$ south west of Addis Ababa, the capital city of Ethiopia. Geographically, the town lies between at $70^{\circ} 41^{\prime} \mathrm{N}$ latitude and $36^{\circ} 50^{\prime} \mathrm{E}$ longitude. The area characterized by humid tropical with bimodal heavy rainfall which is uniform in amount and distribution, ranging from 1200 to $2000 \mathrm{~mm}$ per year, with short and main seasons occurring from mid-February to May and June to September, respectively. The mean annual minimum and maximum temperatures are $6^{\circ} \mathrm{C}$ and $31^{\circ} \mathrm{C}$ respectively. According to the estimate of Ethiopia Jimma town had about 177, 900 human population [22]. The livestock populations of Jimma zone were estimated to be 53,250 heads of cattle; 25,230 heads of sheep; 12,570 heads of goats; 10,030 heads of equine and 90,157 heads of poultry [23]. In town specifically, there is one municipal abattoir and 85 legally registered butcher shops which are directly get slaughter service from the same abattoir of the town. In Jimma Town municipality abattoir, on average, 20-65 heads of cattle are slaughtered daily for local consumption. The cattle slaughtered at Jimma municipal abattoir were originated mostly from different districts of Jimma zone.

\section{Study design and sampling techniques}

A cross-sectional study was conducted from January, 2018 to February, 2019 in Jimma Town. A total of 100 bovine meat samples ( 50 from the abattoir and 50 from butcher shops) were collected by using systematic random sampling from the abattoir while the slaughtered cattle were in the lairage and purposively from legally registered butcher shops. The samples were collected using the method described by [24]. All samples were collected with interval of two weeks and in each visit one hundred grams of meat samples were taken just after the stage of evisceration before washing from different regions of the carcass, such as neck, flank, brisket, and rump region in abattoir. The same amounts of meat samples were taken from the hanged display in the butcher shop outlets to be sold raw to consumers. All samples were collected aseptically using disposable glove to avoid cross contamination. On completion of meat cut process, the meat samples were transferred in sterilized labeled universal bottles and transported in ice-box to Jimma University medical microbiology laboratory for microbiological analysis within one to two hours. Up on arrival, the samples were stored in refrigerator at $4{ }^{\circ} \mathrm{C}$ until being processed.

\section{Sample preparation and processing}

Twenty five grams of the meat sample was weighted weighed and chopped aseptically into small pieces, using sterile knife and transferred into sterile plastic bag contained $225 \mathrm{ml}$ of buffered peptone water (Oxoid Ltd. Hampshire, UK) and homogenized using a laboratory blender (Stomacher 400, Seward, England) at high speed for 2 min and incubated at $30^{\circ} \mathrm{C}$ for $24 \mathrm{~h}$. The resulting suspension was used for isolation and identification of Listeria.

\section{Isolation and identification of Listeria}

Listeria isolation and identification was performed using the techniques recommended by [24]. Briefly, $1 \mathrm{ml}$ of the well mixed BPW suspension was transferred to $9 \mathrm{ml}$ of Listeria Enrichment Broth (Difco Laboratories, USA) and incubated at $37^{\circ} \mathrm{C}$ for $48 \mathrm{~h}$. Then, a loop-full from incubated $L E B$ was streaked on 
PALCAM (Polymixin Acriflavin Lithium Chloride Ceftazidime Aesculin Mannitol) agar (Oxoid, Basingstoke, UK) and OXA (Oxford) agar (Oxoid, Basingstoke, UK) and the plate was incubated at $37^{\circ} \mathrm{C}$ for 24 to $48 \mathrm{hr}$. Then, plate was examined for the presence of Listeria typical grey-green, or greenish black colony, on PALCAM ager and OXA agar were as Listeria species identification respectively. Then, up to 3-5 isolated colonies from each selective medium were picked and streaked into pre-dried Tryptose Soya Yeast Extract Agar (TSYEA) (Difco, Becton, USA) and incubated at $37^{\circ} \mathrm{C}$ for 18 to $24 \mathrm{~h}$ for purification. Then, purified Listeria isolate colonies cultured on TSYEA were subjected to different biochemical tests; Grams staining, catalase, oxidase, and hemolysis tests. Bacteria that appeared as coccoid to rod shaped and Grampositive; formation of gas bubble in $3 \%$ hydrogen peroxide; oxidase test strips no color change; and on sheep blood agar showing narrow, ß-hemolytic colonies were considered presumptively as Listeria spp. as recommended by [24].

\section{Phenotype characterization of listeria species}

Biochemically confirmed the genus of Listeria isolates were kept in sterile labeled (cryovials), aseptically transported to National Animal Health Diagnostic and Investigation Center (NAHDIC); for the Biolog test for further phenotypic characterization of Listeria isolates at species level identification. The phenotypic characterization of Listeria species was performed using manufacturer's instructions (GEN III database, version 5.2). This was done by growing Listeria isolates on Biolog Universal Growth agar (Hayward, USA) with $5 \%$ sheep blood and incubated at $33^{\circ} \mathrm{C}$ for $18-24$ hours. A single colony was selected and emulsified in to a special gelling inoculating fluid. Then, cell density of the bacterial inoculums was measured for a specified transmittance 90 to $98 \%$ using a turbidimeter, as specified in the user guide. For each isolate, $100 \mu \mathrm{l}$ of the cell suspension were inoculated into the GEN III micro plates aseptically, using automatic multichannel pipette into 96 well of plates and incubated at $33^{\circ} \mathrm{C}$ for 18 to 22 hours. After incubation, the micro plates were loaded into the OmniLog reader and analyzed. The result was compared to biolog bacterial identification system software library GEN III database, provided identification of the organisms at species level [25].

\section{Antimicrobial susceptibility tests}

Antimicrobial susceptibility test was performed for Listeria monocytogenes isolates by using disc diffusion method in Muller Hinton Agar with sheep blood supplement. Antimicrobial drugs that are commonly used both in human and veterinary medicine were included in the susceptibility test; namely

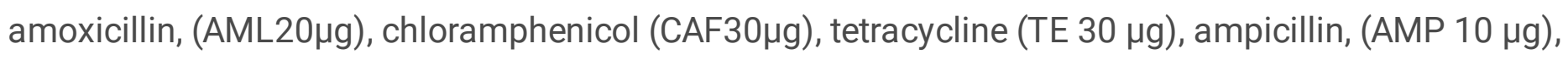
sulfamethoxazole-trimethoprime (SXT $25 \mu \mathrm{g})$, cloxacillin (OX $30 \mu \mathrm{g})$, gentamicin (CN $10 \mu \mathrm{g})$, penicillin ( $\mathrm{P}$ $10 \mu \mathrm{g}$ ), nalidixic acid and vancomycin (VA $30 \mu \mathrm{g})$, (Oxoid Ltd, Basingstoke, Hampshire, England). About 3-5 pure colonies confirmed to be Listeria monocytogenes were suspended in to a tube containing buffered saline. A 0.5 McFarland Standard was used to optimize the suspension for disc diffusion test [26] and transferred to Mueller-Hinton agar plate using a sterile cotton swab. Plate was uniformly spread on the entire agar surface and allowed to dry. Different antimicrobial impregnated disks were applied to the surface of the plates and then incubated aerobically at $37^{\circ} \mathrm{C}$ for 24 hours. Each plate was examined under an indirect light source from lamp to see the growth and inhibition zone around the discs. The 
inhibition zones were measured to the nearest millimeter using sliding caliper. Finally, zone of inhibition was compared with the reference table categorizing as susceptible, intermediate and resistant on the basis of the critical points recommended by clinical and laboratory standards institute [27]. Control strain (S. aureus (ATCC 25923)) was obtained from the Ethiopian public health institute (EPHI), Addis Ababa and included as quality control on each procedure date and each batch of cartridges of antibiotic discs.

\section{Questionnaire survey and Observation checklist}

A structured questionnaire was administered by using face-to-face method to a total of 100 (50 from butcheries shops and 50 from abattoir) purposively selected meat handlers. Direct observational check lists were also used to assess the risk factors contributing to contamination with Listeria on bovine meat along the production chain from the abattoir to butcher shops outlets. The questions were administered within two weeks interval at both abattoir and in butcher shops with the key elements including educational level, attendance of training on meat handling and hygiene, hygienic practices, the use of apron and hair cover, and hygienic status of working equipment and utensils.

\section{Data management and analysis}

Data generated from laboratory investigation and questionnaire survey were recorded and coded using Microsoft Excel for Windows 2007 and transferred to Statistical Package for the Social Sciences (SPSS) version 20.0 (IBM SPSS, 2011). Descriptive analysis was used to describe the study variables. Fisher's exact test was used to calculate the association of positive results with putative risk factors for meat contamination. The strength of association between outcome and explanatory variables was assessed using odds ratios (OR). Finally, those variables with $\mathrm{P}<0.05$ was considered as a statistically significant potential risk factors for Listeria isolates.

\section{Ethical consideration}

Ethical clearance was obtained from the Institutional Review Board (IRB) of Institute of Health, Jimma University. Written consent was obtained from meat handlers working in abattoir and butcher shops. Confidentiality of the information was maintained throughout the study.

\section{Results}

Among a total of 100 meat samples, 29 (29\%; 95\% Cl: 21.0-38.5\%) were positive for Listeria species. Out of this, 15 (30\%, 95\% Cl: 34.4-68.6\%) were isolated phenotypically characterized from butcher shops and 14 (28\%, 95\% Cl: $31.4-65.6 \%)$ were from the abattoir. The dominant $L i s t e r i a$ species isolated was $L$. innocua ( $48 \%$ ) followed by Listeria seeligeri $(28 \%)$, L. welshimeri (10\%) whereas L. monocytogenes and $L$. grayi were the least $(7 \%)$ isolated ones (Table 1$)$. 
Table 1

Listeria species from meat samples in abattoir and butcher shops of Jimma town

\begin{tabular}{|c|c|c|c|c|c|c|}
\hline \multirow[t]{2}{*}{ Sources } & \multicolumn{6}{|l|}{ Listeria species } \\
\hline & L.monocytogenes & L. innocua & L. seeligeri & L. welshimeri & L. grayi & Total \\
\hline Abattoir & $1(7 \%)$ & $8(57 \%)$ & $3(22 \%)$ & $1(7 \%)$ & $1(7 \%)$ & 14 \\
\hline Butcher shops & $1(7 \%)$ & $6(40 \%)$ & $5(33 \%)$ & $2(13 \%)$ & $1(7 \%)$ & 15 \\
\hline Total & $2(7 \%)$ & $14(48 \%)$ & $8(28 \%)$ & $3(10 \%)$ & $2(7 \%)$ & 29 \\
\hline
\end{tabular}

Table 2

Antimicrobial resistance profiles of L. monocytogenes from meat samples

\begin{tabular}{|lllll|}
\hline SN & Antimicrobial agent & \multicolumn{2}{l|}{ Number of isolates (\%) } \\
\cline { 3 - 5 } & & Resistant & Intermediate & Susceptible \\
\hline 1 & Amoxicillin & 0 & 0 & $29(100 \%)$ \\
\hline 2 & Chloramphenicol & $7(24 \%)$ & $6(21 \%)$ & $16(55 \%)$ \\
\hline 3 & Penicillin & $22(76 \%)$ & $2(7 \%)$ & $5(17 \%)$ \\
\hline 4 & Cloxacillin & $29(100 \%)$ & 0 & 0 \\
\hline 5 & Tetracycline & $17(59 \%)$ & $3(10 \%)$ & $9(31 \%)$ \\
\hline 6 & Vancomycin & 0 & 0 & $29(100 \%)$ \\
\hline 7 & Sulfamethoxazole- & 0 & 0 & $29(100 \%)$ \\
\hline 8 & Sulfamethrimethoprim & & 0 & $29(100 \%)$ \\
\hline 9 & Gentamycin & 0 & 0 & 0 \\
\hline 10 & Nalidixic acid & $29(100 \%)$ & 0 & $29(100 \%)$ \\
\hline
\end{tabular}

\section{Antibiotic susceptibility pattern}

The two confirmed isolates of Listeria monocytogenes, one from abattoir and the other from butchers' shop, were assessed for antimicrobial susceptibility pattern with 10 different antibiotics. They were found to be resistance towards cloxacillin, nalidixic acid penicillin. However, the isolates were susceptible to amoxicillin, vancomycin, Sulfamethoxazole-Sulfamethrimethoprim, gentamicin, ampicilin, chloramphenicol and tetracycline

Factors affecting the prevalence of Listeria monocytogenes in meat 
This study demonstrated that the occurrence of Listeria monocytogenes in meat was associated with the socio-demographic characteristics of meat handlers. Educational status of meat handlers was statistically associated with Listeria occurrence $(\mathrm{OR}=2,95 \% \mathrm{Cl}: 0.93-9.6, \mathrm{P}<0.05)$ with higher risk of contamination in respondents with low level of education than those attended primary educational levels. Training related to meat hygiene and handling was statistically associated with Listeria isolates $(\mathrm{OR}=3$, $95 \% \mathrm{Cl}$ : $0.36-5.7, \mathrm{P}<0.05)$ with higher risk of contamination in respondents unattended any training. There was also a difference in the proportion of Listeria positive results among butcher shops and abattoir works in relation to their washing and cleaning practice of knife. The higher frequency of Listeria positive result was seen among sample obtained from workers who do not wash their knives before and after use which was statistically associated with meat contamination with Listeria (OR $=5.4,95 \%$ Cl: $2.1-$ 11.8, $\mathrm{P}<0.05)$ (Table 3). 
Table 3

Fisher's exact test analysis of association of the putative risk factors with Listeria positive result from butcher shops and the municipal abattoir in Jimma town

\begin{tabular}{|c|c|c|c|c|c|c|}
\hline Variables & Categories & Total & $\begin{array}{l}\text { Positive } \\
\text { (\%) }\end{array}$ & $\begin{array}{l}(95 \% \\
\mathrm{Cl})\end{array}$ & $\begin{array}{l}\mathrm{OR}(95 \% \\
\mathrm{Cl})\end{array}$ & $\begin{array}{l}\text { Fishery exact test } P \text { - } \\
\text { value }\end{array}$ \\
\hline \multirow[t]{3}{*}{ Education } & $1-4$ grade & 52 & $\begin{array}{l}17 \\
(32.7)\end{array}$ & $\begin{array}{l}21.5- \\
46.2\end{array}$ & \multirow[t]{3}{*}{$\begin{array}{l}2(1.93- \\
9.6)\end{array}$} & \multirow{3}{*}{$\begin{array}{l}0.035 \\
*\end{array}$} \\
\hline & $5-8$ grade & 36 & $9(25.5)$ & $\begin{array}{l}13.7- \\
41.0\end{array}$ & & \\
\hline & $\begin{array}{l}9-12 \\
\text { grade }\end{array}$ & 12 & $3(25.0)$ & $\begin{array}{l}8.9- \\
53.2\end{array}$ & & \\
\hline \multirow[t]{2}{*}{ Training Attended } & Yes & 29 & $5(17.2)$ & $\begin{array}{l}7.6- \\
34.6\end{array}$ & \multirow{2}{*}{$\begin{array}{l}* \\
3(1.36- \\
5.7)\end{array}$} & \multirow{2}{*}{$\begin{array}{l}* \\
0.02\end{array}$} \\
\hline & No & 61 & 24(39.3) & $\begin{array}{l}28.1- \\
51.9\end{array}$ & & \\
\hline \multirow[t]{3}{*}{ Hygienic practices } & Yes & 45 & $9(20.4)$ & $\begin{array}{l}10.9- \\
33.8\end{array}$ & \multirow{3}{*}{$\begin{array}{l}* \\
2.5(1.5- \\
22.0)\end{array}$} & \multirow{3}{*}{$\begin{array}{l}* \\
0.012\end{array}$} \\
\hline & No & 55 & $20(36.4)$ & $\begin{array}{l}24.9- \\
49.6\end{array}$ & & \\
\hline & No & 33 & $9(27.3)$ & $\begin{array}{l}15.1- \\
44.2\end{array}$ & & \\
\hline \multirow[t]{2}{*}{$\begin{array}{l}\text { Equipment } \\
\text { cleanliness }\end{array}$} & Yes & 44 & $8(18.2)$ & $\begin{array}{l}9.5- \\
31.9\end{array}$ & \multirow{2}{*}{$\begin{array}{l}* \\
5.4(2.1- \\
11.8)\end{array}$} & \multirow{2}{*}{$\begin{array}{l}* \\
0.02\end{array}$} \\
\hline & No & 56 & $21(37.5)$ & $\begin{array}{l}26.0- \\
50.6\end{array}$ & & \\
\hline \multirow[t]{2}{*}{$\begin{array}{l}\text { Butcher Shop } \\
\text { hygiene }\end{array}$} & Good & 20 & $4(20.0)$ & $\begin{array}{l}8.1- \\
41.6\end{array}$ & \multirow[t]{2}{*}{4.4} & \multirow[t]{2}{*}{0.11} \\
\hline & Poor & 30 & $\begin{array}{l}11 \\
(36.7)\end{array}$ & $\begin{array}{l}21.9- \\
54.5\end{array}$ & & \\
\hline \multirow[t]{2}{*}{$\begin{array}{l}\text { White Coat } \\
\text { Hygiene }\end{array}$} & Good & 14 & $4(28.6)$ & $\begin{array}{l}11.7- \\
54.6\end{array}$ & \multirow[t]{2}{*}{3.9} & \multirow[t]{2}{*}{0.14} \\
\hline & Poor & 36 & 11(30.6) & $\begin{array}{l}18.0- \\
46.9\end{array}$ & & \\
\hline \multirow[t]{2}{*}{ Use Hair Coat } & Yes & 20 & $4(20.0)$ & $\begin{array}{l}8.1- \\
41.6\end{array}$ & \multirow[t]{2}{*}{4.4} & \multirow[t]{2}{*}{0.11} \\
\hline & No & 30 & $\begin{array}{l}11 \\
(36.7)\end{array}$ & $\begin{array}{l}21.9- \\
54.5\end{array}$ & & \\
\hline Use Apron & Yes & 30 & $6(27.3)$ & $\begin{array}{l}9.5- \\
37.3\end{array}$ & 5.3 & 0.07 \\
\hline
\end{tabular}




\begin{tabular}{|lllllll|}
\hline Variables & Categories & Total & $\begin{array}{l}\text { Positive } \\
(\%)\end{array}$ & $\begin{array}{l}(95 \% \\
\mathrm{Cl})\end{array}$ & $\begin{array}{l}\text { OR }(95 \% \\
\mathrm{Cl})\end{array}$ & $\begin{array}{l}\text { Fishery exact test P- } \\
\text { value }\end{array}$ \\
\hline & No & 20 & $8(44.4)$ & $\begin{array}{l}21.9- \\
61.3\end{array}$ & \\
\hline
\end{tabular}

\section{Discussion}

The overall prevalence of Listeria species in meat samples was found to be $29 \%$ that indicated significant public health risk associated with consumption of meat. The findings of this study is consistent with the study done in Addis Ababa and Gondar where the prevalence of Listeria species was $27.5 \%$ and $26 \%$ respectively $[15,28]$. However, the present study was higher than the $14 \%$ occurrence reported in Jimma town [29] and 12\% occurrence in Addis Ababa [30]. The variation in detection of Listeria species in foods in different studies could be attributable to the difference in sample type, samples sizes, variations in meat handling and hygienic practices of meat handlers.

In the present study, the predominant identified Listeria species was L. innocua (14, 48\%), L. seeligeri (8, $28 \%)$, L. welshimeri $(3,10 \%)$, L. monocytogenes $(2,7 \%)$ and L. grayib $(2,7 \%)$. In this study, bacteriological examinations showed that raw bovine meat was found contaminated with Listeria species in both abattoir and butcher shops. This might be due to raw bovine samples were exposed to contaminants during slaughtering, processing and retailing. This finding is in agreement with report of [30].

In this study, L.monocytogenes isolates were found to be resistant to cloxacillin, tetracycline, nalidixic acid penicillin. This finding is in agreement with the previous report of $[16,17,31,32,33]$. This may be attributed to the indiscriminate use of these antimicrobial agents in food producing animals at subtherapeutic levels or prophylactic doses resulted in the emergence of antimicrobial-resistant strains to certain antimicrobials $[16,20,33,34]$. In developing countries there is a wide spread and uncontrolled usage of this antimicrobials due to its relatively cheaper price and easily accessibility. Penicillin and tetracycline are one of the most frequently prescribed drugs for most of infectious diseases in veterinary medicine that could be mentioned as one of the reasons for the development of increased resistance profile $[16,35,36]$. Therefore, such antimicrobial resistant $L$. monocytogenes isolates in raw meat products has an important public health implication. In contrary, L. monocytogenes isolates had showed high susceptibility to gentamicin, vancomycin, sulfamethoxazole, chloramphenicol and cloxacillin which is in agreement with previous studies [6, 16,37].

In this study, the butcher shop and abattoir workers who had a low level of education (1-4) were statistically associated with Listeria meat contamination $32.78 \%(95 \% \mathrm{Cl}: 21.5-46.2 \%$; $\mathrm{P}<0.05)$. This finding is in agreement with the report of $[38,39]$. Studies have shown that butcher shop and abattoir workers who had low level of education were not adhering with strict hygienic practices and standard slaughtering practices which lead to microbial contamination of meat [40,41]. 
Likewise, meat samples examined from butcher shops and abattoir workers who did not attend any training regarding meat hygiene and handling practices were statistically associated with contamination of meat by Listeria 39.3\% (95\% Cl: $28.1-51.9 \% ; \mathrm{P}<0.05)$. Several reports showed that, the workers working in the abattoir and butcher shops in most cases in developing countries are untrained and thus, they pay no attention to the hygienic standards and as result contribute immensely to bacterial contamination [43]. Therefore, food safety training of meat handlers about the basic concept and requirements of personal hygiene and its environment plays an important part in safeguarding the quality of meat products $[42,44,45]$.

In this study, the use of unclean equipment in butcher shops and abattoir was statistically associated with Listeria meat contamination $37.5 \%$ (95\% Cl: 26.05-50.6\%; $\mathrm{P}<0.05)$. This finding is in agreement with other findings $[46,47]$. This could be due to numerous cross-contamination risks exist in primary food production systems especially at the point lairage, slaughter processes and post-harvest handling due to unclean knives, working surface and utensils [48].

Conclusion: The overall proportion of Listeria positive samples from raw bovine meat in this study was $29 \%$ (95\% Cl: $21.0-38.5 \%)$. Out of these, 15 (30\%, 95\% Cl: 34.4-68.6\%) and 14 (28\%, 95\% Cl: $31.4-65.6 \%)$ were isolated in the samples collected from butcher shops and abattoir of Jimma town respectively. The dominant Listeria species isolated was L. innocua (48\%). The presence of Listeria species both in the abattoir and butcher shops of Jimma town have been attributed to unhygienic meat handling practices. This turn influenced by lack of on job training and use of unhygienic equipments and meat contact surfaces. Therefore, there is a need for periodic training on hygienic meat handling practices for meat handlers at each stage of meat production chain.

\section{Abbreviations}

BPW: Buffered Peptone Water; Cl: Confidence Interval; CLSI: Clinical Laboratory Standards Institute; GEN III: Generation III; ISO: International Standardization Organization: Listeria Enrichment Broth; MHA: Muller Hinton Agar; OR: Odd Ratio; OXA: Oxford Agar; PALCAM:

Polymixin Acriflavin Lithium Chloride Ceftazidime Aesculin Mannitol; SPSS: Statistical Package for Social Sciences

\section{Declarations}

\section{Acknowledgments}

The authors would like to acknowledge the Environmental Health Sciences and Technology, and Medical Microbiology Laboratories of Jimma University and Sabata National Animal Health Diagnostic and Investigation Center for allowing the laboratory facilities. The authors are grateful to the owners of the study establishments and study participants.

\section{Funding}


This work was supported by grant obtained from Jimma University. The funding organization had no role in formulating the study design, data collection, analysis and interpretations. The views presented in this paper are the sole responsibilities of the authors and do not reflect views of the funder.

\section{Author's contributions}

STM conceived the research idea, wrote the protocol, drafted data collection tools and revised the manuscript. AG and BG wrote the protocol, collected data, performed data analysis and drafted the initial manuscript. YD, TK, LS, DT, HB, LB and SS revised the proposal and the draft manuscript. All authors read and approved the manuscript.

\section{Availability of data and materials}

All the data pertaining to the manuscript can be obtained from the corresponding authors upon request.

\section{Ethical approval and consent to participate}

Ethical clearance was obtained from ethical review board of Jimma University Institute of Health Sciences. Written consent was obtained from Zonal and district administrations; abattoirs and butcher shops. All information from each study participant was obtained after informed and written consent was made and it was kept confidential.

\section{Consent for publication}

The authors declare that the manuscript does not contain any personally identifiable information

\section{Competing interests}

The authors declare that they have no competing interests.

\section{References}

1. Addis Z, Kebede N, Sisay Z, Alemayehu H, Wubetie A, Kassa T. Prevalence and antimicrobial resistance of Salmonella isolated from lactating cows and in contact humans in dairy farms of Addis Ababa: A cross sectional study. BMC Infect Dis. 2011;11:222.

2. Zelalem A, Moti Y, Zelalem A. Food-Borne Bacterial Diseases in Ethiopia. J Nutr. 2015;1:62-76.

3. Lowe D, Robbins J, Bakardjiev A. Animal and human tissue models of vertical Listeria monocytogenes transmission and implications for other pregnancy-associated infections. Infect Immun. 2018;86:801-17.

4. WHO. Initiative to estimate the Global Burden of Food-borne Disease 2012.

5. Edget A, Degmar N, Birutesfa A. Review on common food borne pathogens in Ethiopia. Afr J Microbiol Res. 2014;53:4027-40. 
6. Pal M. Mahendra R. Sanitation in Food Establishments (1st Edn). LAP Lambert Academic Publishing, Saarbruchen, Germany 2015.

7. Komba V, Mkupasi E, Mbyuzi A, Mshamu S, Mzula A, Luwumbra D. Sanitary practices and occurrences of zoonotic conditions in cattle at slaughter in Morogoro Municipality, Tanzania; Implication for public health. Tanzan J Health Res. 2012;14:2.

8. Pal M. The Complete Book on Waste Treatment Technologies. 1st ed. New Delhi: Nirr Project Consultancy Services, Kamala Nagar; 2015.

9. Conficoni D, Losasso C, Cortini E, Cesare A, Cibin V. Giaccone, V. Resistance to biocides in Listeria monocytogenes collected in meat processing environments. Front Microbiol. 2016;7:1627.

10. Guillet C, Lambert J, Monnier A, Leclercq A, Mechai F, Bruneel M, Bieleck M, Scortti M, Disson O, Berche P, Boland V, Lortholary O, Lecuit M. Human Listeriosis Caused by Listeria Ivanovii. Emerg Infect Dis. 2010;16:136-8.

11. Pagliano P, Arslan F, Ascione T. Epidemiology and treatment of the commonest form of listeriosis: meningitis and bacteraemia. Infez Med. 2017;25:210-6.

12. Abdollahzadeh E, Ojagh S, Hosseini H, Irajian G, Ghaemi E. Prevalence and molecular characterization of Listeria spp. and Listaria monocytogenes isolated from fish, shrimp, and cooked ready-to-eat (RTE) aquatic products in Iran. Food Sci and Technol. 2016; 73: 205-211.

13. Wu S, Wu Q, Zhang J, Chen M, Yan A, Hu H. Listeria monocytogenes prevalence and characteristics in retail raw foods in China 2015.

14. EFSA. The European Union summary report on trends and sources of zoonoses, zoonotic agents and food-borne outbreaks in 2014. EFSA Journal. 2016;13:4329.

15. Derra A, Karlsmose S, Monga P, Mache A, Svendsen A, Felix B, Granier A, Geyid A, Taye G, Hendriksen R. Occurrence of Listeria species in retail meat and dairy products in the area of Addis Ababa, Ethiopia. Ethiopian Health Nutrition Research Institute. 2013;6:577-9.

16. Garedew L, Taddesea A, Birut T, Nigatu S, Kebede E, Ejo M, Fikru A, Birhanu T. Prevalence and antimicrobial susceptibility profile of Listeria species from ready- to-eat foods of animal origin in Gondar Town, Ethiopia. BMC Microbiol. 2015;15:100.

17. Girma Y, Abebe B. Isolation, identification and antimicrobial susceptibility of Listeria species from raw bovine milk in Debre-Berhan town, Ethiopia. Journal of Zoonotic Diseases Public Health. 2018;2:1-4.

18. Ndahi M, Kwaga J, Bello M, Kabir J, Umoh V, Yakubu S, Nok A. Prevalence and antimicrobial susceptibilityof Listeria monocytogenes and methicillin resistant Staphylococcus aureus strains from raw meat and meat products in Zaria, Nigeria. Lett Appl Microbiol. 2014;58:262-9.

19. Su X, Zhang J, SHI W, Yang X, Li Y, Pan H, Kuang D. Molecular characterization and antimicrobial susceptibility of Listeria monocytogenes isolated from foods and humans. Food Control. 2016;70:96-102.

20. Allen K, Walecka-Zacharska E, Chen J, Katarzyna K, Devlieghere F, Meeryenne E, Bania JL.. monocytogenes: An examination of food chain factors potentially contributing to antimicrobial 
resistance. Food Microbiol. 2016;54:178-89.

21. Wilson A, Gray J, Chandry P, Fox E. Phenotypic and genotypic analysis of antimicrobial resistance among Listeria monocytogenes isolated from Australian food production chains. Genes. 2018;9:80.

22. CSA Central Statistical Agency. [Ethiopia]. National Population Census Report of Ethiopia. Addis Ababa.2015.

23. CSA Central Statistical Agency. Livestock sample Survey.2012; 2011-2012.

24. ISO International Standardization Organization. Microbiology of food and animal feeding stuffshorizontal method for the detection and enumeration of. In: Listeria monocytogenes.part1: Detection method ISO 11290-1.Geneva. Switzerland: International Organization for Standardization; 1996.

25. Wragg P, Randall L, Whatmore AM. Comparison of Biolog GEN III Micro-Station semi-automated bacterial identification system with matrix-assisted laser desorption ionization-time of flight mass spectrometry and $16 \mathrm{~S}$ ribosomal RNA gene sequencing for the identification of bacteria of veterinary interest. J Microbial Methods. 2014;105:16-21.

26. Bauer AW, Kirby WMM, Sherris JC, Turck M. Antibiotic susceptibility testing by a standardized single disk method. Am J Clin Pathol. 1966;45:493-6.

27. CLSI Clinical and Laboratory Standards Institute: Performance for antimicrobial disk susceptibility tests; approved standard, 26th edition. CLSI document M100S. Wayne (PA), USA.2016; 5:1-76.

28. Simon G, Tesfu K, Haile A, Kahsay H, Nigatu K. Isolation and characterization of Listeria monocytogenes and other Listeria species in foods of animal origin in Addis Ababa. Ethiopia Journal of Infection Public Health. 2011;4:22-9.

29. Wosila M, Diriba M, Yoseph D, Abebaw G, Molalegne B. Studies on occurrence of L. monocytogenes and other species in milk and milk products retail market of Jimma town, Ethiopia. Asian J Dairy Food Res. 2013;32:35-9.

30. Molla B, Yilma R, Alemayehu D. Listeria monocytogenes and other Listeria species in retail meat and milk products in Addis Ababa, Ethiopia. Ethio J Health Dev. 2004;18:208-12.

31. Gomez E, Azo N, Marco J, Rota C. Antimicrobial resistance of Listeria monocytogenes and Listeria innocua from meat products and meat-processing environment. Food Microbiol. 2014;42:61-5.

32. Navratilova P, Schlegelova J, Sustackova A, Napravnikova E, Lukasova J, Klimova E. Prevalence of Listeria monocytogenes in milk, meat and foodstuff of animal origin and the phenotype of antibiotic resistance of isolated strains. Journal of Veterinary Medicine. 2004;49:243-52.

33. Nayak J, Brahmbhatt M, Sadariya K. Studied on in- vitro sensitivity and resistance pattern of Listeria spp. from raw meat against antimicrobial drugs. International Journal of Pharmaceutical Science. 2012;30:103-17.

34. Sharma D, Sharma PK, Saharan BS, Malik A. Isolation, identification and antibiotic susceptibility profiling of antimicrobial resistant Listeria monocytogenes from dairy milk. Int J Microbial Res Techno. 2012;1:1-4. 
35. Wilson A, Gray J, Chandry P, Fox E. Phenotypic and genotypic analysis of antimicrobial resistance among Listeria monocytogenes isolated from Australian food production chains. Genes. 2018;9:80.

36. Remya K, Sunil C, Lathal Vrinda M, Ashok K. Prevalence of Listeria species in meat processing environments. Int J Curr Microbiol App Sci. 2014;2:542-6.

37. Munita M, Arias A. Mechanism of antibiotics resistance. Microbiology spectrum. 2016;4:2.

38. Firehiwot A. Prevalence and antimicrobial profile of Listeria monocytogenes in retail meat and dairy products in Addis Ababa and its surrounding towns, Ethiopia. MSc thesis, Addis Ababa University, Addis Ababa, Ethiopia; 2007.

39. Gurmu E, Gebretinsae H. Assessment of bacteriological quality of meat contact surfaces in selected butcher shops of Mekelle city, Ethiopia. J Environ Occup Sci. 2013;2:61-6.

40. Ntanga P, Mdegela R, Nonga $\mathrm{H}$. Assessment of beef microbial contamination at abattoir and retail meat shops in Morogoro Municipality, Tanzania. Tanzania Veterinary Journal. 2014;29:0856-1451.

41. Bhandare G, Paturkar M, Waskar S, Zende J. Bacteriological screening of environmental sources of contamination in an abattoir and the meat shops in Mumbai, India. Asian J Food Ag-Industry. 2009;3:280-90.

42. Crandall P, Neal J, Brya C, Murphy C, Marks B. Ricke S. Minimizing the risk of Listeria monocytogenes in retail delis by developing employee focused, cost effective training. Journal of Agriculture Food Analytical Bacteriology. 2011;1:159-74.

43. Haileselassie M, Taddele H, Adhana K, Kalayou S. Study on food safety knowledge and practices of abattoir and butchery shops and the microbial profile of meat in Mekelle City, Ethiopia. Asian Pac J Trop Biomed. 2013;5:407-12.

44. Elizabeth A, William A, Lian F, Thomas S, Barend M. Working conditions and public health risks in slaughterhouses in western Kenya. BMC Public Health MC series open inclusive trusted. 2017;17:14.

45. Roberts K, Barrett B, Howells A, Shanklin C, Pilling VK, Brannon L. Food Safety Training and Foodservice Employees Knowledge and Behavior. J Food Prot Trends. 2008;28:252-60.

46. Park S, Kwak T, Chang H. Evaluation of the food safety training for food handlers in restaurant operations. Nutr Res Pract. 2010;4:58-68.

47. Niyonzima E, Ongol M, Brostaux Y, Koulagenko N, Daube G, Kimonyo A, Sindic M. Consumption patterns, bacteriological quality and risk factors for Salmonella contamination in meat-based meals consumed outside the home in Kigali. Rwanda Food control. 2017;73:546-54.

48. Hua L, Pengfei W, Ruiting L, Lijuan L, Xiaolong C, Yi Wang Y, Hui L. Risk Factors and Level of Listeria monocytogenes Contamination of Raw Pork in Retail Markets in China. Front Microbiol. 2018;9:1090. 